\title{
Dietary advice: foods or nutrients
}

\author{
B Y D. A. T. SOUTHGATE \\ AFRC Institute of Food Research, Norwich Laboratory, Norwich Research Park, Colney Lane, \\ Norwich NR4 $7 U A$
}

There is considerable debate over the content of dietary advice to be given to individuals within the United Kingdom, and most other industrialized countries, and the most effective way of presenting this advice. In the present paper I would like to debate the merits of giving advice in terms of recommendations about nutrients or in terms of foods. In doing this I will not be concerned in detail with the content of the advice, nor with whether it should be directed at all the individual members of the population or targeted at the 'at-risk' members (Rose \& Day, 1990).

In this debate I start from the premise that dietary advice should provide the individual with the basis for action in choosing the appropriate diet for himself or herself. This is true even when the target relates to the diet of the population as a whole, because the diet of the population is de facto the sum of the diets eaten by the individuals who comprise that population and any dietary change that follows the advice is the sum of all the changes made by individuals. Individuals, not populations, choose the food they consume.

In order for dietary advice to be effective, two essential criteria must be fulfilled. First, the individual must understand the advice sufficiently to be able to assess his or her current diet and to be able to make the appropriate changes to that diet so that it conforms with the advice given. Second, the individual must be motivated to comply with the advice. I do not propose to discuss this aspect further, but unless the motivational issues are addressed, dietary advice, however soundly based and excellently presented, will fail to achieve its objectives. Furthermore, it is, I think, important to recognize that advice by its very nature may be accepted or rejected and I suspect that as a general proposition most advice, dietary or otherwise, is rejected. Therefore, when we consider the form that dietary advice should take, we should consider how well the advice will be understood and form the basis for action.

\section{BARRIERS TO UNDERSTANDING}

One way of addressing this issue is to examine the possible barriers to understanding that may exist and to see whether expressing the advice in terms of nutrients in foods is likely to reinforce or reduce these barriers. I would like to suggest that there are three principal barriers to understanding: the nature of the evidence, the language and terms used, and the form in which the advice is presented. The debate between the relative merits of expressing the advice in terms of foods or nutrients is principally concerned with the second and third barriers, but it is worth saying a little about the first.

\section{THE NATURE OF THE EVIDENCE}

There are a number of factors here which in fact have their roots in the scientific methods that we use. First, epidemiological associations are often misunderstood and often 
deliberately distorted and translated into causal relationships. Second, the meaning of increased or reduced risk (Rose \& Shipley, 1990) and its significance for the individual are difficult concepts to relay to a statistically naïve audience, an audience, moreover, that is often bombarded with statistical data that are interpreted to support whichever cause the politician, economist or activist wishes to promote. The difficulties involved in interpreting the significance of population risks for the individual are, I suspect, one of the more potent factors reducing the motivation to comply with any advice.

Third, the testing of hypotheses by attempting to falsify them experimentally is not the way that the media, politicians and the advertising industry, the most powerful communicators to the general public, operate, so that the way in which scientific concepts are tested and refined may be seen as evidence of confusion.

\section{THE LANGUAGE USED IN THE ADVICE}

The choice of the language used in the presentation of the dietary advice is especially important for understanding and this is one aspect of the debate where giving the advice in terms of nutrients may reduce the level of comprehension.

First, many of the scientific terms used to describe nutrients are not part of everyday language and those terms that are commonly used, such as, protein, calories, vitamins or dietary fibre, are often interpreted in a nutritionally naïve sense. I doubt whether a group of accredited nutritionists has a common perception of what some of these words really mean, nor of the amounts of these constituents there are in their diets. More specialized terms such as polyunsaturated fatty acids and complex concepts such as "non-milk extrinsic sugars' may fail to convey any real messages to the consumer despite their unexceptional scientific validity (Ministry of Agriculture, Fisheries and Food, 1990a).

There is another point concerning the language that we use in dietary advice; this is the quantitative nature of the advice. To those for whom measurement is the centre of their working lives, with a high level of numeracy, concepts such as fat intake as a percentage of energy consumption, $\mathrm{g}$ dietary fibre, $\mathrm{mg}$ iron, $\mu \mathrm{g}$ folates, etc., present no real problems of interpretation (Yeomans, 1986). This level of familiarity with units and the numeracy required to use and manipulate these quantitative concepts are not shared by most of those to whom dietary advice is addressed.

Using nutrients in this context, because the names are outside normal language and usage will force the consumer to translate the nutrients into the terms which they do use, namely, foods; the process of translation produces associations that may be only partially correct, so that dietary fibre may be interpreted as wheat bran, and bread and cereals are identified with carbohydrates. In the case of fats, all animal fats are seen as saturated and all plant fats as unsaturated. The quantitative complexity of foods as mixtures of proteins, different classes of fatty acids combined in triacylglycerols, different types of carbohydrates and as sources of a range of inorganic nutrients and vitamins can be lost and at best, may seem to the individual as further evidence of confusion in the minds of nutritionists and makes dietary advice even more difficult to understand.

Thus, it would appear that it would be more effective to use the language of the consumer in the presentation of dietary advice. This means talking about foods and combinations of foods in meals and in the daily diet. In most types of dietary advice there is a need for the advice to be quantitative and this is particularly important for determining the form in which the dietary advice is presented. 


\section{THE FORM IN WHICH THE DIETARY ADVICE IS PRESENTED}

This is one of the major barriers to consider because it relates to both understanding and more importantly to implementation.

Virtually all current dietary advice is predicated on the proposition that the present pattern of nutrient consumption in industrialized countries is a major factor in the incidence of chronic disease, and the advice, therefore, is directed at leading to dietary changes in those individuals whose diets have an unsatisfactory composition (Department of Health and Social Security, 1984; US Department of Health and Human Services, 1988).

In clinical practice dietary advice is given to a patient who may need to reduce energy intake because of obesity, control energy, fat and carbohydrate intakes because of diabetes mellitus, or to reduce fat and cholesterol intake because of a hyperlipidaemia. In each of these examples the diet being consumed has been assessed and, therefore, one has objective data to show that changes to the diets are indicated as part of the management of the conditions. When advice is given to all individuals within a population, even when the primary purpose is to influence the dietary intake of the population, it is evident that a proportion of that population will have a dietary intake that already conforms with the advice and, therefore, who could expect no benefit from change (Rose \& Day, 1990).

Thus, the first requirement is for the advice to be such that the individual is able to assess his or her own diet and to compare it with the advice. In order to assess the relative merits of advice in terms of foods or nutrients it is instructive to take an example of current dietary advice and to make an analysis of the processes that the advice requires of the individual for its implementation.

The Committee on Medical Aspects of Food Policy (COMA) recommendations (Department of Health and Social Security, 1984) provide a fairly typical example that includes advice in terms of nutrients, and in some cases foods, so the advice is a suitable model. The advice is summarized in Table 1.

This advice can be considered as a number of stages: I have presented the advice in a different order from the COMA report (Department of Health and Social Security, 1984) because the implementation of the advice logically starts from energy intake. The stages involved in implementing this advice are set out in the flow diagram (Fig. 1).

This shows that the individual must assess their body-weight and then estimate the

Table 1. Recommendations of the Committee on Medical Aspects of Food Policy Panel on Diet in Relation to Cardiovascular Disease (Department of Health and Social Security, 1984)

Energy intake
$\begin{aligned} & \text { Energy intake and physical exercise should be regulated so that body-weight } \\ & \text { is maintained within the acceptable range }\end{aligned}$
The consumption of saturated and total fat should be reduced to $15 \%$ and
$35 \%$ of energy intake respectively
Sugar intake
Complex carbohydrates
The consumption of foods containing these should be increased to
compensate for the fat reductions
Consumption should not increase and ways to reduce it be sought




\title{
Assess body weight $\rightleftharpoons$ Ideal body weights
}

\author{
Assess energy intake

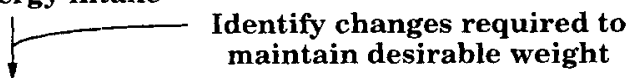 \\ Target energy intake
}

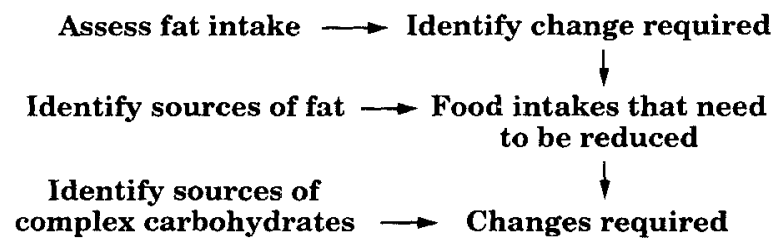

Fig. 1. Stages involved in the implementation of dietary advice as implied by the Committee on Medical Aspects of Food Policy recommendations (Department of Health and Social Security, 1984).

appropriate energy intake to maintain or bring the body-weight down to lie within the ideal range. The second stage is the estimation of the composition of the diet in terms of the percentage energy derived from total fat and saturated fat. Using an analysis of the sources of fat in the diet, the appropriate target foods that are sources of fat are identified. This provides the basis for deciding the amounts by which the intake of these foods should be reduced and the amounts of complex-carbohydrate-containing foods to meet the energy from fat reductions are identified.

Thus, implementation requires a series of calculations that depend on a knowledge of ideal body-weight coupled with the computation and nutritional analysis of the diet eaten. I suggest that this is a series of operations that many nutritionists would find difficult without a computer and that it is not practicable as a long-term procedure for anyone, nutritionist or not, to form the basis for choosing the appropriate diet.

This was recognized by the COMA panel because the recommendations include some statements about foods, especially in identifying sources of complex carbohydrates. The panel also recommended that foods should be labelled with their fat content and their content of saturated fats to assist in making the changes to fat intake. The panel also recognized that the consumers would need to be given education in order to be able to implement the recommendations.

The authors of the National Advisory Committee on Nutrition Education (NACNE) discussion paper (Health Education Council, 1983) who recognized the importance of quantitative nutritional guidelines couched their guidance in terms of nutrients but intended this guidance for the professional nutrition educators who, they anticipated, would translate this quantitative nutrient-based guidance into more readily usable terms, i.e. foods and diets, for the general public.

\section{GUIDANCE IN TERMS OF FOODS}

If one accepts that guidance in terms of foods would be more easily understood by the consumer, because this uses more familiar language, and because we eat foods rather than nutrients per se; the major problem to be faced is the quantification of the advice. 
Traditional dietary guidance of the type given before the introduction of quantitative nutritional goals by the McGovern report (Senate Committee on Nutrition and Human Needs, 1977) and the NACNE paper (Health Education Council, 1983) most commonly used an approach based on food groups and was at best semi-quantitative and usually used such terms as 'moderate' and 'eat regularly' or 'infrequently'. If quantitative guidance is desirable then this type of advice would not lead to effective implementation because the terms 'moderate' or 'infrequently' are capable of very wide interpretation. It is, therefore, necessary when advice is given in terms of foods to give advice about the relative proportions of different foods within the dietary mixture.

Sherman (1933) uses the relative proportions of expenditure on different types of food and it is interesting to see how this approach translates today (Table 2; Ministry of Agriculture, Fisheries and Food, 1990b). In advice based on foods it is most convenient to use some form of grouping of foods so that one has groups that are relatively homogeneous in respect of the nutrients they provide. The groups also have to be ones that the consumer can identify and accept. One recent example of advice which is primarily food-based is that of the US Surgeon General (US Department of Health and Human Services, 1988). These are summarized in Table 3. The advice is generally positive, i.e. 'choose foods relatively low in fats especially saturated fats', or 'increase consumption of whole-grain foods and cereal products, and vegetables'. Thus, the advice tacitly assumes that most individuals need to implement dietary changes. Only one recommendation requires the individual to assess their current diet and this relates to energy and the control of body-weight.

Table 2. Balancing diet by expenditure

\begin{tabular}{lcc}
\hline & Percentage of total food expenditure \\
\cline { 2 - 3 } & & $\begin{array}{c}\text { Ministry of Agriculture, } \\
\text { Fisheries and Food (1990b) }\end{array}$ \\
\hline Vegetables and fruit & $\geqslant 20$ & $21 \cdot 1$ \\
Milk and cheese & 20 & $14 \cdot 0$ \\
Meat, fish, eggs & $\leqslant 20$ & $35 \cdot 5$ \\
Bread and cereal foods & $\geqslant 20$ & $16 \cdot 7$ \\
Fats, sugars, groceries & $\leqslant 20$ & $12 \cdot 6$ \\
\hline
\end{tabular}

Table 3. Recommendations for most people (US Department of Health and Human Services, 1988)

$\begin{array}{ll}\begin{array}{l}\text { Achieve and maintain desirable body-weight } \\ \text { Reduce consumption of fat (especially saturates) }\end{array} & \begin{array}{l}\text { Match intake:expenditure; increase physical activity } \\ \text { Choose foods that are relatively low in these fats: } \\ \text { lean meat, poultry, fish, low-fat dairy foods }\end{array} \\ \begin{array}{l}\text { Increase consumption of whole-grain and cereal } \\ \text { products, vegetables and fruits }\end{array} & \text { Choose lower salt content foods } \\ \text { Reduce salt intake } & \text { Up to two drinks/d }\end{array}$


The National Research Council (1989) in its extremely detailed examination of the evidence on diet and health expresses its recommendations in a mixture of quantitative nutrient recommendations, qualified by advice on how this may be achieved in terms of foods, both positive 'choose' and negative 'reduce', phraseology is used. Most of the advice is not quantitative but some is (Table 4). Thus, the frequency and amounts of vegetables, fruits and cereal foods recommended are given. The advice on energy intakes is linked to the control of body-weight. In many respects the advice is semi-quantitative, 'moderate' intakes of protein are recommended and an 'adequate' intake of calcium. The advice assumes that all individuals would benefit by changing their dietary intake.

I do not believe that giving dietary advice in this way is entirely satisfactory for two reasons. First, the advice is not quantitative, it does not go far enough towards guiding the individual on constructing the diet. Second, by identifying foods that are to be reduced, because the advice is not quantitative, effectively creates a group of foods that are seen as undesirable and translated by many as 'unhealthy'.

\section{ADVICE IN TERMS OF THE DIET AS A WHOLE}

So far I have argued that expressing dietary advice in terms of nutrients creates barriers of language and difficulties in implementation and that advice in terms of foods is at present not quantitative and leads itself to misinterpretation.

The evidence that we have is that the habitual consumption of diets with a certain composition are associated with increased health risk. The dietary effects are due to the integrated effects of the diet consumed over a longer period than days or weeks; therefore, our dietary advice should be based on advice over a period of time. The emphasis should be on eating a mixture of foods over that period and our quantitative advice should be given as the proportions of foods (in suitable groups). Ideally the implementation should be as simple as possible; thus, a system analogous to that used for the diabetic subjects in some countries regarding the proportions of foods on a notional plate. This coupled with the cooperation of the food producers, both primary and secondary, in reducing the fat content of meats and meat products and an expansion of the currently available ranges of low-fat dairy foods should achieve the dietary changes for which there is good evidence that benefits to health would accrue.

Table 4. Dietary recommendations (National Research Council, 1989)

\begin{tabular}{|c|c|}
\hline $\begin{array}{l}\text { Reduce total fat to } 30 \% \text { of energy } \\
\text { Reduce saturated fat to } 10 \% \\
\text { Cholesterol to below } 300 \mathrm{mg}\end{array}$ & $\begin{array}{l}\text { Substitute fish, poultry, lean meats, low-fat dairy } \\
\text { products }\end{array}$ \\
\hline $\begin{array}{l}\text { Every day eat five or more servings of vegetables } \\
\text { and fruits }\end{array}$ & Especially green, yellow vegetables and citrus fruits \\
\hline \multicolumn{2}{|l|}{ Eat six or more servings of bread, cereals and legumes } \\
\hline $\begin{array}{l}\text { Balance intake and physical activity } \\
\text { Alcohol is not recommended, advisory limit on } \\
\text { consumption of two drinks/d }\end{array}$ & \\
\hline
\end{tabular}




\section{REFERENCES}

Department of Health and Social Security (1984). Diet and Cardiovascular Disease Committee on Medical Aspects of Food Policy Report of the Panel on Diet in Relation to Cardiovascular Disease. Report on Health and Social Subjects no. 28. London: H.M. Stationery Office.

Health Education Council (1983). A Discussion Paper on Proposals for Nutritional Guidelines for Health Education in Britain. London: National Advisory Committee on Nutrition Education.

Ministry of Agriculture, Fisheries and Food (1990a). Food Labelling Survey England and Wales. London: H.M. Stationery Office.

Ministry of Agriculture, Fisheries and Food (1990b). Household Food Consumption and Expenditure 1989. Annual Report of the National Food Survey Committee. London: H.M. Stationery Office.

National Research Council (1989). Diet and Health: Implications for Reducing Chronic Disease Risk. Report of Committee on Diet and Health, Food and Nutrition Board, Commission on Life Sciences. Washington, DC: National Academy of Sciences.

Rose, G. \& Day, S. (1990). The population mean predicts the number of deviant individuals. British Medical Journal 301, 1031-1034.

Rose, G. \& Shipley, M. (1990). Effects of coronary risk reduction on the patterns of mortality. Lancet 335, 275-277.

Senate Committee on Nutrition and Human Needs (1977). Dietary Goals for the United States. Washington, DC: US Government Printing Office.

Sherman, H. C. (1933). Chemistry of Food and Nutrition, 4th ed., pp. 522-526. New York: Macmillan.

US Department of Health and Human Services (1988). The Surgeon General's Report on Nutrition and Health. Washington, DC: US Government Printing Office.

Yeomans, L. (1986). Practical Use of Nutrition Labels. Nutrition Bulletin no. 46, pp. 12-22. London: British Nutrition Foundation. 